Available online on 15.06.2020 at http://jddtonline.info
Open Access to Pharmaceutical and Medical Research
(c) 2011-18, publisher and licensee JDDT, This is an Open Access article which permits
unrestricted non-commercial use, provided the original work is properly cited

Open $\odot$ Access

Research Article

\title{
A Study on Drug Utilization of Antibiotics in Respiratory Tract Infections among Geriartrics
}

\author{
Sripuram Charave1, Reshmi Suresh', Shihab1, Mohammed Fayiz¹, Apoorva Dev*2 \\ 1Pharm D Interns, Department of Pharmacy Practice, PES University, Bengaluru, Karnataka, India-560 050 \\ ${ }^{2}$ Assistant Professor, Department of Pharmacy Practice, PES University, Bengaluru, Karnataka, India-560 050
}

\begin{abstract}
Back ground: Respiratory Tract Infections (RTIs) often pose a major threat for geriatric patients ( $>60$ years) who are at higher risk of developing complications. The first line treatments for RTIs are antibiotics which help in reducing the infection. As there is increasing incidence of antimicrobial resistance it is necessary to conduct drug utilization of antibiotics which helps in better understanding about errors and risks
\end{abstract} involved in prescriptions.

Objectives: The objective of the study is to access the prescribing pattern, appropriate use of antibiotics and inappropriateness of antibiotics in viral infections.

Methodology: The present study is a prospective observational study. The study included 110 patients which included the evaluation of the patients medical records of antibiotics, sputum culture reports and physician records.

Results: Out of 110 geriartric RTI patients, female (59.09\%) were more predominantly affected over males (40.90\%). Among the RTIs diagnosed pneumonia (40\%) was higher followed by LRTI (28.18\%). The common signs and symptoms found were breathlessness (34.54\%) with major comorbidity of diabetes milletus (47.31\%). Piperacillin + tazobactam (40.90\%) was the mostly prescribed antibiotic for both gram positive (Streptococci) and gram negative (E. coli) bacteria which was given through I.V. (90\%). Total drug interactions and medication errors were $13.03 \%$ and $3.32 \%$ respectively.

Conclusion: The present study gives an overview of antibiotics use and complications involved in geriatric population diagnosed with RTIs Appropriate antibiotic usage according to Hospital Antibiotic Policy was observed in the study site with lower number of medication errors and drug interactions.

Key words: Respiratory Tract Infections, drug utilization, antibiotics, geriatrics.

Article Info: Received 24 March 2020; Review Completed 20 May 2020; Accepted 27 May 2020; Available online 15 June 2020

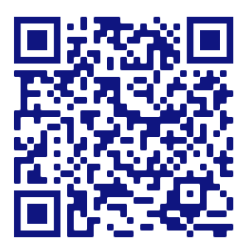

Cite this article as:

Charave S, Suresh R, Shihab, Fayiz M, Dev A, A Study on Drug Utilization of Antibiotics in Respiratory Tract Infections among Geriartrics, Journal of Drug Delivery and Therapeutics. 2020; 10(3-s):61-67

http://dx.doi.org/10.22270/jddt.v10i3-s.4084

Mrs. Apoorva Dev, Asst. Professor, Department of Pharmacy Practice, P.E.S. University, Hanumanth nagar, Bengaluru, Karnataka, INDIA - 560 050 .

\section{INTRODUCTION}

The respiratory tract constitutes a large body portion that is in contact with the outside environment. Although there are presences of non-pathogenic microbes found during microbiological testing, still the tract is considered to be sterile. Therefore an invasion of pathogenic microorganisms into the tract represents a series of threat that requires immediate immune responses ${ }^{1}$. In South-East region, of the total 3,941,000 deaths, Respiratory Tract Infections (RTIs) accounts for $34.60 \%$ deaths $^{2}$.

In most of the developing countries, the burdens of RTIs are largely unknown ${ }^{3}$. RTIs account for more restricted activity and loss of time from work than any other category of infections ${ }^{4}$. Exposure of variable individuals to infectious agents, infectious dose and pathogen virulence drive differences in the frequency of respiratory infections. The rating of infectious disease risk depends on several environmental factors and lifestyle habits ${ }^{5}$. Infectious respiratory diseases include common cold, bronchitis, bronchiolitis, pneumonia, tuberculosis whereas non infectious respiratory diseases include chronic obstructive pulmonary disease, asthma, occupational lung disease and pulmonary malignancies.

There are mainly of two types of infectious respiratory disease: upper and lower respiratory tract infections. Upper Respiratory Tract Infection (URTI) is a nonspecific term which is used to describe acute infections that involves nose, 
paranasal sinuses, pharynx, larynx, trachea and bronchi.This can lead to illnesses such as common cold, tonsillitis, pharyngitis, laryngitis, sinusitis, otitis media that constitute $87.5 \%$ of the total episodes of respiratory infections. On the other hand Lower Respiratory Tract Infection (LRTI) comprises of acute bronchitis, acute exacerbation of chronic bronchitis, pneumonia and pleurisy ${ }^{6}$. In a systematic analysis conducted in 2015, LRTIs caused 2.74 million deaths and 103 million Disability Adjusted Life-Years worldwide (DALYs) making them the second leading cause of DALYs?.

Lack of relevant information about etiological agents results in inappropriate use of drugs. Therefore, the detection of a potentially causative agent forms the prerequisite for proper treatment and an early detection of virus can reduce the rates of irrational and overuse prescription. Due to the emergence of an increasing number of multi-drug resistant bacteria, respiratory infections due to bacterial origin have become a global concern ${ }^{8}$. Antibiotics are the oldest class of drugs that fight against specific micro organisms like bacteria and fungi ${ }^{9}$. There are more than 100 million antibiotic prescriptions in an adult ambulatory care hospital set up per year, out of these $41 \%$ are for respiratory conditions ${ }^{10}$.

As age increases, frequent health related issues also arise and that include frailty, polypharmacy, under use of medication, inappropriate prescribing, medication errors, comorbidity conditions, pharmacokinetic and pharmacodynamics changes affecting the absorption, distribution, metabolism and excretion of drugs ${ }^{11}$.

Another area of concern is seen in medication errors with respect to prescriptions. According to NCC MERP, Medication Error (ME) is defined as "any preventable event that may cause or lead to inappropriate medication use or patient harm while the medication is in control of the health care professional, patient, or consumer. Such events may be related to professional practice, health care products, systems and procedures, including prescribing, order communication, product labelling, packaging, nomenclature, compounding, dispensing, distribution, administration, education, monitoring and use ${ }^{12}$.

Drug Utilization Review (DUR) is defined as an authorized, structured, ongoing review of prescribing, dispensing and use of medication. Drug utilization studies play a major in our health care system and it also provides a view about the efficiency of drug use. As a result they help us to set up priorities for rational use of antibiotics and health care budgets. In India there is no sufficient data which gives insight about the respiratory tract infection, resistance patterns and proper guidelines for rational use of antibiotics. So DUR studies provide information about prescribing antibiotics for even mild cases, selling the antibiotics over the counter without prescriptions. It helps to generate a relevant data regarding the issues present currently ${ }^{13}$.

The purpose of the study is to determine average number of antibiotics prescribed per prescription, to identify the indication for which antibiotics were commonly used and to determine the most commonly prescribed antibiotic in respiratory infections in a secondary care hospital ${ }^{14}$.

\section{Objectives:}

\section{Primary objectives}

- To carry out drug utilization review of antibiotics in respiratory tract infections among geriatrics in a secondary care hospital.
- To provide effective management suggestions based on the study results for improved health care in geriatrics.

\section{Secondary objectives}

- To access the pattern of antimicrobial drug utilization among geriatric patients in the current study site.

- To foster the appropriate use of antibiotics for respiratory tract infections.

\section{MATERIALS AND METHODS}

\section{Study site:}

Excel Care Multispecialty Hospital, Bengaluru, Karnataka, India.

\section{Study design:}

A prospective observational hospital based study.

\section{Study period:}

Carried out for a period of six months.

\section{Inclusion criteria}

○ Both male and female patients of age 60 years and above.

- Patients diagnosed with respiratory tract infections.

- Patients who are prescribed with antibiotics.

\section{Exclusion criteria}

○ Patients under the age of 60 years.

- Patients who stay less than 24 hours in the hospital.

- Accident cases and patients with altered consciousness.

- Patients diagnosed with pulmonary malignancies and occupational lung diseases.

\section{Source of data:}

Patient's case notes.

\section{Study procedure:}

A prospective observational study was conducted in the pulmonary department of Excel Care Multi-Specialty hospital by obtaining approval from the hospital for a period of 6 months. A specially planned case reporting performa was designed to collect data such as demographics, diagnosis, current complaints, past medical and medication history, known allergies, laboratory reports (chest X-ray), full antibiotics received, antibiotics prescribed on admission, route of antibiotic administration, duration of antibiotics given to the patient throughout his/her hospital stay was collected.

The collected data was analyzed for the age and gender distribution, number of comorbidities, route of administration, distribution of RTIs, average number of antibiotics prescribed per prescription, most prescribed antibiotic, drug interactions through Micromedex drug interaction app, adverse drug reactions and medication errors.

\section{Result analysis:}

The collected data was subjected to Descriptive Statistical Analysis using Microsoft Excel. 


\section{RESULTS}

A prospective observational study was conducted over a period of 6 months at Excel Care Multispeciality Hospital, Bengaluru. During the study, 110 geriatric patients were enrolled diagnosed with respiratory tract infections.

Table 1: Gender distribution

\begin{tabular}{|c|c|c|}
\hline Gender & No. of prescriptions & Percentage (\%) \\
\hline Male & 45 & 40.90 \\
\hline Female & 65 & 59.09 \\
\hline Total & 110 & 100 \\
\hline
\end{tabular}

Table 1 depicts that; out of 110 patients involved, the percentage of female $(59.09 \%)$ was found to be more. when compared to males $(40.90 \%)$. Therefore, females were found to be the predominant gender.

From the Table 2; age groups between $60-79$ are more prone to incidence of respiratory tract infections.

As seen in Table 3; pneumonia was found to be the major type of respiratory infection involved with a total of 44 $(40 \%)$ cases and least was with Bronchiectasis with 2 $(1.81 \%)$ cases.
Table 2: Distribution of patients according to age (in years) group

\begin{tabular}{|c|c|c|}
\hline Age & No. of prescritions & Percentage \\
\hline $60-69$ & 40 & $36.36 \%$ \\
\hline $70-79$ & 41 & $37.27 \%$ \\
\hline $80-89$ & 23 & $20.90 \%$ \\
\hline $90-100$ & 6 & $5.45 \%$ \\
\hline Total & 110 & $100 \%$ \\
\hline
\end{tabular}

Table 3: Distribution of patients according to the type of RTI

\begin{tabular}{|c|c|c|}
\hline Distribution of RTIs & No. of patients & Percentage (\%) \\
\hline Pneumonia & 44 & 40 \\
\hline LRTI & 31 & 28.18 \\
\hline COPD & 16 & 14.54 \\
\hline Viral Pneumonia & 5 & 4.54 \\
\hline Bronchial Asthma & 3 & 2.72 \\
\hline Bronchiectasis & 2 & 1.81 \\
\hline
\end{tabular}

Table 4 represents that breathlessness (34.54\%) was the frequent problem that the patients faced.

Table 4: Signs and symptoms

\begin{tabular}{|c|c|c|}
\hline Signs and symptoms & No. of patients affected & Percentage (\%) \\
\hline Breathlessness & 38 & 34.54 \\
\hline Cough with expectoration & 28 & 25.45 \\
\hline Wheezing & 17 & 15.45 \\
\hline Cough with Whitish sputum & 13 & 11.81 \\
\hline Cough with yellowish sputum & 10 & 9.09 \\
\hline Fever & 9 & 8.18 \\
\hline Cold & 8 & 7.02 \\
\hline Throat irritation & 3 & 2.72 \\
\hline Cough with greenish sputum & 3 & 2.72 \\
\hline
\end{tabular}

Table 5: Gram positive bacteria

\begin{tabular}{|c|c|c|}
\hline Gram positive bacteria & No. of patients & Percentage \\
\hline Streptococci & 10 & $9 \%$ \\
\hline
\end{tabular}

Table 6: Gram negative bacteria

\begin{tabular}{|c|c|c|}
\hline Gram negative bacteria & No. of patients & Percentage \\
\hline E. coli & 8 & $7.27 \%$ \\
\hline Pseudomonas aeruginosa & 7 & $6.36 \%$ \\
\hline Influenza H1N1 & 6 & $5.45 \%$ \\
\hline Klebsiella pneumonia & 5 & $4.50 \%$ \\
\hline \multicolumn{2}{|c|}{ Total } & $\mathbf{2 3 . 5 8 \%}$ \\
\hline
\end{tabular}

From Table 6; the gram-negative E. coli bacteria was found to be higher 8 (7.27\%) followed by Pseudomonas aeruginosa 7 $(6.36 \%)$. The distribution of gram-negative bacteria was more common than gram-positive bacteria. 
From Table 7 and Figure 1; the infection due to both gram-positive and gram-negative bacteria was most commonly treated with Piperacillin/Tazobactam (7).

Table 7: Distribution of antibiotic therapy in accordance with respective isolated organisms

\begin{tabular}{|c|c|c|c|c|c|}
\hline Antibiotics & Streptococci & $\begin{array}{c}\text { Pseudomonas } \\
\text { aeruginosa }\end{array}$ & $\begin{array}{c}\text { H1N1 } \\
\text { influenza }\end{array}$ & $\begin{array}{c}\text { E. coli } \\
\text { Klebsiella } \\
\text { pneumonia }\end{array}$ \\
\hline Piperacillin/Tazobactam & 7 & & 4 & 3 & 5 \\
\hline Cefoperazone/Salbactam & 3 & 3 & & 1 & \\
\hline Ceftriaxone & & 1 & & & \\
\hline Cefixime & & 1 & & & \\
\hline Cefipime & & 1 & & & \\
\hline Clarithromycin & & 1 & & & \\
\hline Azithromycin & & 1 & & & \\
\hline Doxycycline & & 1 & & & \\
\hline Colistimethate sodium & & & & & \\
\hline
\end{tabular}

\section{ANTIBIOTICS AND ORGANISMS}

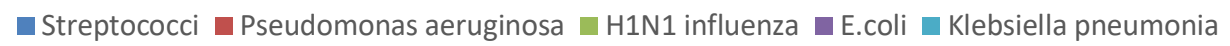
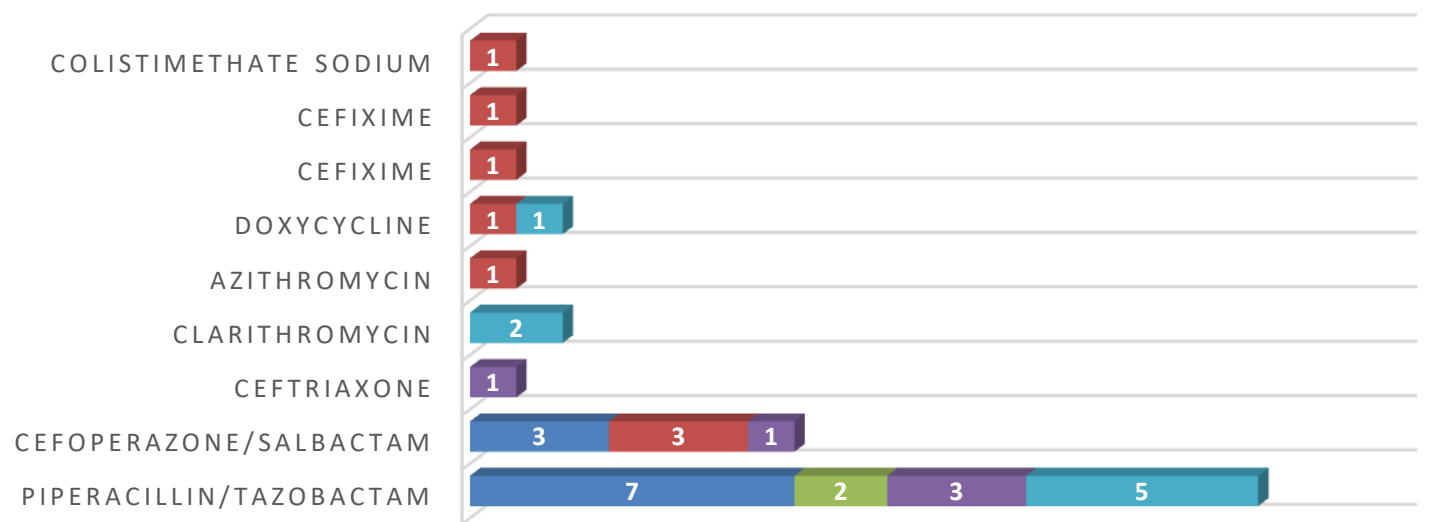

Figure 1: Distribution of antibiotics and isolated organism

From Table 8; 51 (46.36\%) prescriptions had one antibiotic, followed by 38 (34.54\%) prescriptions with 2 antibiotics, $15(13.63 \%)$ prescriptions with 3 antibiotics, 5 (4.54\%) prescriptions with 4 and prescriptions with 5 antibiotics was found only $1(0.90 \%)$, which was the maximum number prescribed throughout the hospital stay.

Table 8: Number of antibiotics per prescription

\begin{tabular}{|c|c|c|}
\hline No. of antibiotics & No. of prescriptions & Percentage \\
\hline 1 & 51 & $46.36 \%$ \\
\hline 2 & 38 & $34.54 \%$ \\
\hline 3 & 15 & $13.63 \%$ \\
\hline 4 & 5 & $4.54 \%$ \\
\hline 5 & 1 & $0.90 \%$ \\
\hline Total & 110 & $100 \%$ \\
\hline
\end{tabular}

The commonly prescribed antibiotic under RTI was found out by counting the total number of antibiotic and classifying them into the respective drug classes. From Table 9 and Figure 2 Piperacillin + Tazobactam combination (39) was the most prescribed Antibiotic under RTI, followed by doxycycline (21).

Table 9: Commonly prescribed antibiotics

\begin{tabular}{|c|c|c|}
\hline Antibiotics & $\begin{array}{c}\text { No. of } \\
\text { antibiotics }\end{array}$ & Percentage \\
\hline Piperacillin + Tazobactam & 39 & $35.45 \%$ \\
\hline Doxycycline & 21 & $19.09 \%$ \\
\hline Clarithromycin & 15 & $13.63 \%$ \\
\hline Cefoperazone + Sulbactam & 14 & $12.72 \%$ \\
\hline Amoxicillin + Clavulanate & 8 & $7.27 \%$ \\
\hline Levofloxacin & 8 & $7.27 \%$ \\
\hline Ceftriaxone & 6 & $5.45 \%$ \\
\hline Meropenam & 5 & $4.54 \%$ \\
\hline Cefixime & 4 & $3.63 \%$ \\
\hline Cefuroxime & 4 & $3.63 \%$ \\
\hline Cefotaxim & 3 & $2.72 \%$ \\
\hline Azithromycin & 3 & $2.72 \%$ \\
\hline
\end{tabular}




\section{COMMONLY PRESCRIBED ANTIBIOTICS}

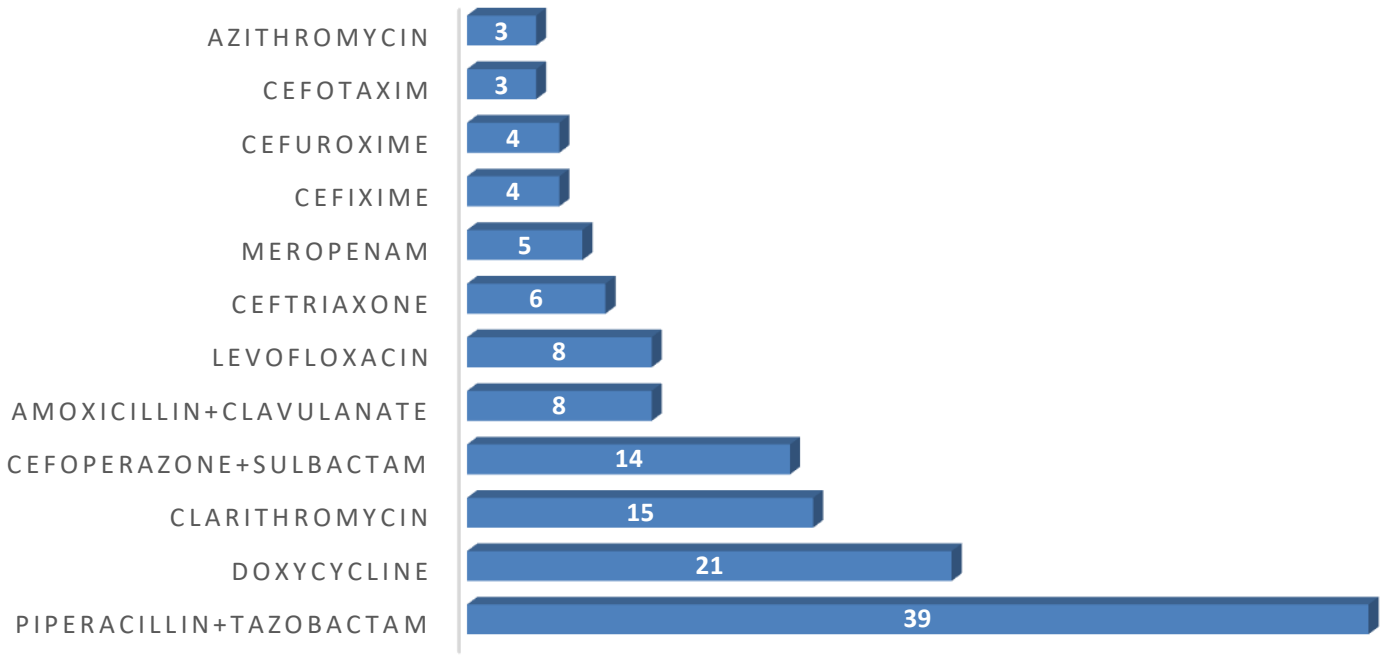

Figure 2: Commonly prescribed antibiotics

Table 10: Number of antibiotic + antibiotic interactions observed in the study

\begin{tabular}{|c|c|c|}
\hline $\begin{array}{c}\text { Antibiotic + antibiotic } \\
\text { interactions }\end{array}$ & Total no. of prescriptions & Percentage \\
\hline 13 & 110 & $11.81 \%$ \\
\hline
\end{tabular}

As seen in Table 10 and Figure 3; the number of interactions between antibiotics was found to be less i.e., out of 110 prescriptions the interactions were $13(11.81 \%)$.

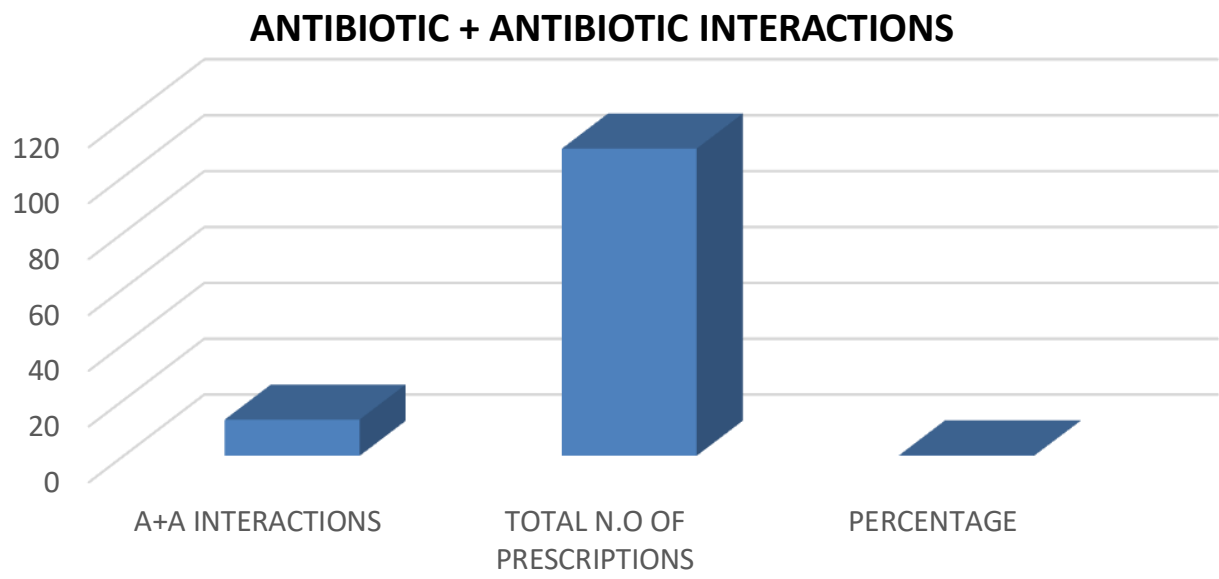

Figure 3: Number of antibiotic + antibiotic interactions in the study

Table 11: Number of antibiotic + other drug interactions observed in the study

\begin{tabular}{|c|c|c|}
\hline $\begin{array}{c}\text { Antibiotic + other drug } \\
\text { interaction }\end{array}$ & No. of prescriptions (110) & Percentage \\
\hline Major & 32 & $29.09 \%$ \\
\hline Moderate & 8 & $7.27 \%$ \\
\hline Minor & 5 & $4.50 \%$ \\
\hline
\end{tabular}




\section{ANTIBIOTIC + DRUG INTERACTIONS}

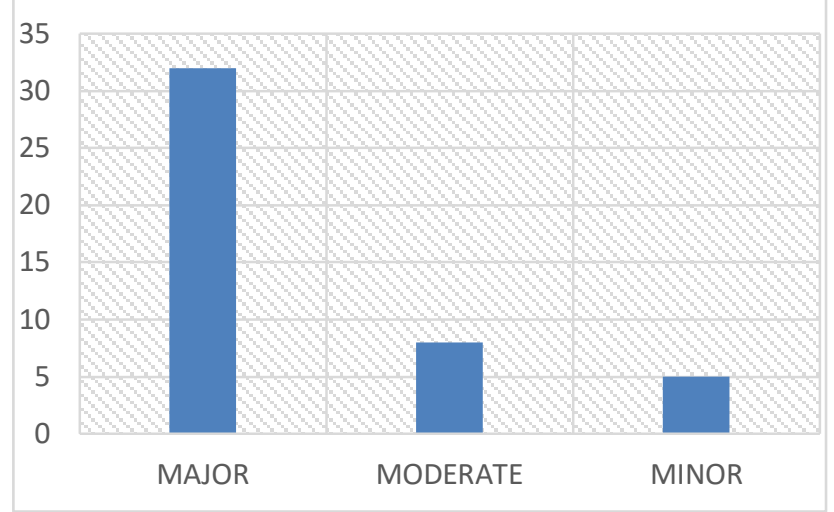

Figure 4: Number of antibiotic + other drug interactions in the study

From the Table 11 and Figure 4; the maximum drug interactions observed were Major 32 (29.09\%) in nature, followed by moderate, and minor. Moderate interactions were $8(7.27 \%)$ in number and Minor were $5(4.50 \%)$ in number.

Table 12: Number of medication errors in the study

\begin{tabular}{|c|c|c|}
\hline $\begin{array}{c}\text { Medication } \\
\text { errors }\end{array}$ & $\begin{array}{c}\text { No. of } \\
\text { prescriptions }\end{array}$ & Percentage \\
\hline Dose & 6 & $5.45 \%$ \\
\hline Frequency & 3 & $2.72 \%$ \\
\hline ROA & 2 & $1.81 \%$ \\
\hline \multicolumn{3}{|c|}{ Average $\mathbf{3 . 3 2 \%}$} \\
\hline
\end{tabular}

Evidence from Table 12, suggests that in the current study the number of prescriptions with medical error was less and the percentage of ME was 3.32\%.

Table 13 depicts that bronchodilators (81.81\%) were the most prescribed class of drugs other than antibiotics followed by anti-diabetes (40\%).

Table 13: Class of drugs other than antibiotics

\begin{tabular}{|c|c|c|}
\hline Class of drugs & No. of prescriptions & Percentage (\%) \\
\hline Anti-virals & 10 & 9.09 \\
\hline
\end{tabular}

\section{DISCUSSION}

Older patients are addressed with more respiratory infections when compared with younger populations. Antibiotics being the first line treatment in respiratory tract infections that combat specific micro organisms; the more consumption of the drug increases its resistance that becomes a major threat to public health. This requires the pharmacist to intervene and develop strategies aimed towards better patient care and improving the quality of life of the patients, especially special populations like the geriatrics. As shown in Table 2, in the current study; out of a total number of 110 prescriptions analysed, females showed higher percentage $65(59.09 \%)$ occurrence of RTI when compared to male 45 (40.09\%). Therefore, females are more predominant and from Table 1; age groups between 60-79 showed more incidence RTIs.

E Hak, Rovers ${ }^{15}$ et.al. shared same evidence on their study on Incidence of GP-diagnosed Respiratory Tract Infections according to age, gender and high risk morbidity. The incidence rates of RTIs were higher in females 103 than in males 74 per 1000 patients.

All the patient profile forms were analysed to find the major type of RTI responsible for hospital admission. From Table 3 Pneumonia was found to be the major type of infection involved with a total of $44(40 \%)$ cases presented with a common symptom of breathlessness (34.54\%) followed by cough with expectoration (25.45\%) as shown in Table 4.

A study conducted on Pneumonia and Hospitalizations in the Elderly by Francessco Cacciatore et.al. showed higher incidence of Pneumonia in geriatrics when compared to all other RTIs. The study showed 25-44 per 1000 cases with an incidence of Community Acquired Pneumonia ${ }^{16}$.

From Table 6; the distribution of gram-negative E. coli $(7.27 \%)$ bacteria was found to be higher. The prevalence of gram-negative bacteria causing infection was more significant compared to gram-positive bacteria as shown in Table 5; Piperacillin/Tazobactam was the most commonly prescribed antibiotic for both gram-positive (Streptococci) and gram-negative (E. coli).

As shown in Table 8; of the total number of prescriptions (110), 51 (46.36\%) prescriptions had one antibiotic, followed by $38(34.54 \%)$ prescriptions with 2 antibiotics, 15 (13.63\%) prescriptions with 3 antibiotics, 5 (4.54\%) prescriptions with 4 and with 5 antibiotics was found only 1 (0.90), which was the maximum number of antibiotics prescribed throughout the hospital stay.

In the current study the commonly prescribed antibiotic under RTI was found out by counting the total number of antibiotic and classifying them into respective drug classes. From Table 9 and Figure 2, Piperacillin+Tazobactam 39 (35.45\%) was the commonly prescribed combination drug and doxycycline $21(19.09 \%)$ was the commonly prescribed monotherapy belonging to the class of Penicillins $+\beta$ Lactamase inhibitor and tetracyclines respectively. Penicillin+b-lactamase inhibitors have activity against many gram-positive and gram-negative bacteria.

The number of interactions between the antibiotics was found to be less i.e., out of 110 prescriptions, Antibiotic interactions were $13(11 \%)$ from Table 10 and Figure 3. The most commonly found interactions were between Piperacillin/Tazobactam and Doxycycline. This interaction can lead to decreased antibacterial effectiveness, so monitoring is advised.

From Table 11 and Figure 4; the maximum drug interactions observed were major 32 (29.09) in nature, followed by moderate and minor. Moderate interactions were 8 (7.27\%) and minor were $5(4.50 \%)$ in number.

The NCC MERP has classified medication error into 9 classes as depicted by the above figure. In our study, 11 medication errors were found in total. The event of not prescribing the Dose occurred in a total of $6(5.45 \%)$ cases, while the event of not prescribing the frequency occurred in a total of 3 $(2.72 \%)$ cases and Route of Administration $2(1.81 \%)$ as shown in Table 12. According to NCC MERP classification, these events fall under the Category A (Circumstances or events that have the capacity to cause error).

Oseltamivir (9.09\%) was the drug that has been given to patients diagnosed with viral infections other than antibiotics as shown in Table 13.

Kevin T Shiley, MD et.al. from their study on the use of antimicrobial agents after diagnosis of Viral Respiratory Tract Infections has shown that Oseltamivir was given to 30 
(21\%) out of 142 patients with influenza. Our study suggests that there is a necessity to monitor medication errors like frequency, dose and route of administration of antibiotics though errors are minimal. Out of total prescriptions evaluated, the percentages of drug interactions were found to be very low. Even though the number of errors and interactions are less, still strict monitoring is advised to eliminate the possible RI 17 .

\section{CONCLUSION}

A prospective observational study on drug utilization of antibiotics was successfully carried out in 110 geriatric patients diagnosed with Respiratory Tract Infections. In our study the most commonly prescribed antibiotic was Piperacillin and tazobactam.

Based on the current antibiotic policy of the hospital in which the study was conducted the first line antibiotic agents are Piperacillin/tazobactam and cephalosporins of higher generations; the second line antibiotics were Amoxicillin/clavulanic acid if penicillin allergy is present, Macrolides and other alternatives are Cephalosporins. In case of previous antibiotic resistance detected Meropenem is prescribed by previous culture reports. The study shows evidence that the medical practitioners are strictly adhering to Hospital Antibiotic Policy in prescribing antibiotics.

Though in the current study the percentage of drug interactions and medication errors were low still proper evaluation is required. This is done by collecting complete and correct data so that the right medication can be prescribed for the indicated condition, all the prescriptions must be thoroughly checked for medication errors, drug interactions; also correct dose, frequency and ROA must be clearly mentioned for every prescription. This may sometime lead to other unnecessary complications.

\section{Limitations}

$>$ The period of study was six months which was very limited to carryout observations in a wider aspect.

$>$ Information on anti-viral agents was limited.

\section{Future Directions}

$>$ The study can be carried out in a larger population by creating multiple study sites.

$>$ Antimicrobial susceptibility testing could give a better overview on newer or emerging antimicrobial resistance.

$>$ Using the study results hospital antibiotic drug policy can be framed.

\section{ACKNOWLEDGEMENT}

We wish to express our sincere gratitude and heartfelt thanks to our guide Mrs. Apoorva Dev, Asst. Professor, Department of Pharmacy Practice, PES University, Bengaluru, Dr. Srinivasan, Head of Pharmacy Practice Department, PES University, and co-guide Dr. Suma P Kumar, Excel Care Multispecialty Hospital, Bengaluru, Karnataka. Their wide knowledge, encouragement and personal guidance enabled us to finish the project successfully.

\section{CONFLICTS OF INTEREST}

The author declares that there is no conflict of interest to disclose.

\section{REFERENCES}

1. Khan S, Priti S, Ankit S. Bacteria etiological agents causing lower respiratory tract infections and their resistance patterns. Iranian Biomedical Journal 2015; 19(4):240.

2. Akanbi MO, Ukoli CO, Erhabor GE, Akanbi FO, Gordon SB. The burden of respiratory disease in Nigeria. Afr J Respir Med 2009; 4:10-7.

3. Naik HG, Khanwelkar CC, Kolur A, Desai R, Gidamudi S. Drug utilization study on antibiotics use in the upper respiratory tract infection. International Journal of Recent Trends in Science and Technology 2014; 10(12):299-302.

4. Nieters A, Weber S, Elgizouli M. Screening score to identify people prone to respiratory tract infections in the community. Int J Respir Med 2017; 2(1):6-13.

5. Shamim, M., M. D. Ali, M. S. Alam, M. S. Ali, S. Ahmad, and M. S. Ansari. "Drug utilization based ADRs detection of antibiotics prescribed for lrti in tertiary care teaching hospital, New Delhi". International Journal of Pharmacy and Pharmaceutical Sciences 2018; 10(4):7-14.

6. Tchatchouang S, Bigna JJ, Nzouankeu A, Fonkoua MC, Nansseu JR, Ndangang MS, Kenmoe S, Penlap VB, Njouom R. Prevalence of respiratory bacterial infections in people with lower respiratory tract infections in Africa: the BARIAFRICA systematic review and meta-analysis protocol. BMJ open. 2018; 8(9):e023592.

7. Andersen P. Pathogenesis of lower respiratory tract infections due to Chlamydia, Mycoplasma, Legionella and viruses. Thorax 1998; 53(4):302-7.

8. Ahmed MM, ELMaraghy AA, Andrawas EW. Study of prescription patterns of antibiotics in treating lower respiratory tract infections at Sohag Chest Hospital. Egyptian Journal of Chest Diseases and Tuberculosis 2016; 65(1):14355

9. Harris AM, Hicks LA, Qaseem A. Appropriate antibiotic use for acute respiratory tract infection in adults. Annals of Internal Medicine 2016; 165(9):674.

10. Etebu E, Arikekpar I. Antibiotics: Classification and mechanisms of action with emphasis on molecular perspectives. Int J Appl Microbiol Biotechnol Res 2016; 4:90101.

11. Battula P, Reddy TM, Prasad TD, Diviti R. A Prospective Study on inappropriate Drug utilization in Geriatric Patients at A Tertiary Care Teaching Hospital. Indian Journal of Pharmacy Practice 2016; 9(3):179.

12. J.Mark Ruscin. Drug Related Problems in Elderly. https://www.msdmanuals.com/professional/geriatrics/drug -therapy-in-older-adults/drug-related-problems-in-olderadults

13. Parthasarathy G, Nyfort-hansen K, Milap N. Clinic Pharmacy Book: Essential Concepts and Skills. Pp. 362-72.

14. Gogineni Vinutna, Mallela Babji, Reshma Namburi, Raj Kumari. Drug utilization study in patients with acute respiratory tract infections at a tertiary care hospital in Bhimavaram, India. International Journal of Advance Research, Ideas and Innovations in Technology 2018: 3(9):

15. Hak E, Rovers MM, Kuyvenhoven MM, Schellevis FG, Verheij TJ. Incidence of GP-diagnosed respiratory tract infections according to age, gender and high-risk co-morbidity: the Second Dutch National Survey of General Practice. Family practice. 2006; 23(3):291-4.

16. Cacciatore F, Gaudiosi C, Mazzella F, Scognamiglio A, Mattucci I, Carone M, Ferrara N, Abete P. Pneumonia and hospitalizations in the elderly. GC [Internet]. 17May2017 [cited 14Apr.2019]; 3(1). Available from: https://www.pagepressjournals.org/index.php/gc/article/vi ew/6377

17. Shiley KT, Lautenbach E, Lee I. The use of antimicrobial agents after diagnosis of viral respiratory tract infections in hospitalized adults: antibiotics or anxiolytics?. Infection Control \& Hospital Epidemiology 2010; 31(11):1177-83. 